\title{
Scenic road designation in Taiwan
}

\author{
S.-H. Lee ${ }^{1,2}$, C.-C. Chiang ${ }^{3}$ \& J.-S. Hou ${ }^{4}$ \\ ${ }^{1}$ Department of Architecture, Feng Chia University, Taiwan \\ ${ }^{2}$ University of Sydney, Australia \\ ${ }^{3}$ Landscape Architecture Program in School of Natural Resources and \\ Environment, University of Michigan, USA \\ ${ }^{4}$ Department of Landscape Architecture, Tunghai University, Taiwan
}

\begin{abstract}
Since 1979, the scenic road movement in Taiwan has promoted the conservation of and connections between landscapes of particular natural, ecological, and cultural value. Scenic road segments have been designated in national and regional comprehensive plans. Alteration or improvement of these segments including their adjacent landscapes must maintain their visual quality. However, due to the lack of established practices to plan and manage designated scenic road segments, the visual quality of many of these road corridors have been negatively impacted. These impacts have been resulted from recent changes in both roads and adjacent land uses regarding urban sprawl and increased traffic demand. In this study, a systematic evaluation framework is established for reassessing and rating existing scenic road segments. This framework incorporates both a landscape quality assessment and a recreational quality assessment. Landform, land-cover, land-use, vegetative cover, etc., are used to define landscape assessment units within each road segment. Thus the diversity of landscapes in the same road segment can be considered. The evaluation scores are used to examine whether existing scenic road segments are qualified to be a national level scenic road or potential scenic road. This holistic and systematic scenic road system can be used to better guide future road and adjacent land-use developments. The evaluation framework is reviewed by experts in the fields of scenic roads and public officials involved with scenic road designations and management. The Taiwanese experience provides a model for conserving landscapes along road corridors in other countries with regions facing development pressure.
\end{abstract}

Keywords: scenic roads, landscape quality assessment, land-use development. 


\section{Introduction}

Taiwan comprises the main island of Taiwan and several small islands and is located in the Western Pacific between Japan and the Philippines. The total area of Taiwan is about 37,000 square kilometres, inhabited by about 23 million people. The majority of population and economic activities (e.g., farming activities, and industries) are distributed in the $31 \%$ plain areas. The rest of the landscape of Taiwan is composed of $38 \%$ hills and terraces between 100 and 1,000 meters above sea level, and about $31 \%$ high mountains over 1,000 meters, Taiwan Government Information Office [1]. The limited available land for development has resulted in the encroachment of urban development and the expansion of economic activities to rural and natural areas.

Since 1979, the scenic road movement in Taiwan has resulted in designating four national park roads as scenic roads in the Comprehensive Development Plan for the Taiwan area. By 2002, 78 scenic road segments were designated in the National Scenic Road Development Plan, fig. 1, to reorganize nationwide designated scenic road segments. However, these plans were devoid of detailed surveys and systematic analyses to rank the importance level of the character of the visual landscape in these segments. Without this ranking, public officials and the public cannot perceive the need of preserving important scenic road segments under urban development pressure and increased traffic demand. Their visual quality has been diminished by recent changes such as broadened road surface areas or adjacent urbanized lands. Thus, a holistic and systematic scenic road system is essential to prevent these random and uncontrolled changes. The aim of this research is to develop a systematic landscape evaluation framework for reassessing and rating existing scenic road segments. Then, the evaluation result can be used to guide future road and adjacent land development regarding the maintenance of visual quality.

\section{Scenic road concept and landscape quality assessment}

\subsection{Concept of scenic roads}

The visual character of landscapes has been suggested to possibly affect emotional attachments to the land, Parsons and Daniel [2] and the overall quality of travellers' experiences, Daniel and Vining [3], which are derived from the scenic encounters with preferred landscapes. Thus, the scenic road concept emphasizes the provision of aesthetic experiences of great natural beauty, or cultural or historical value for travellers while moving along scenic roads, although roads link destinations, Daniel and Vining [3]. This experiential appeal provided by scenic roads not only benefits the individual who experiences them, but establishes an attractive contextual framework for the experience of each destination that is connected by them. In addition, based on the enhancement of the overall attraction of an area, Zube [4, 5] suggests that scenic roads can be associated with extended economic benefits by stimulating the potential of a region's tourism. Therefore, the scenic road concept can be used as a planning tool for environmental conservation and community development. 


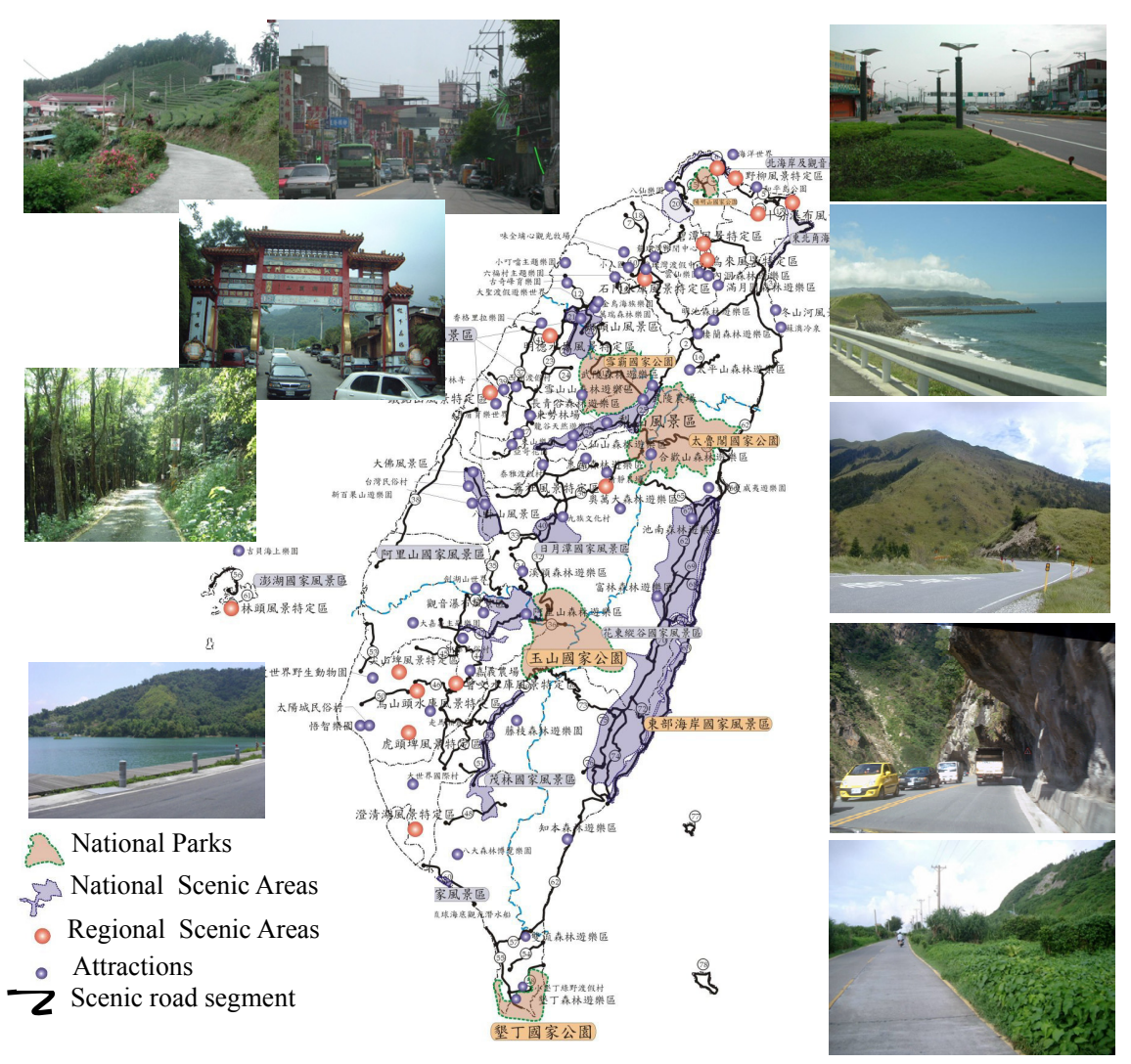

Figure 1: Seventy-eight designated scenic road segments in four regional development plans

\subsection{Landscape quality assessment}

To qualify scenic roads that need to be managed, a systematic landscape quality assessment is generally required. The expert/design approach and public perception-based approach are two main streams of landscape quality assessment found in the literature (e.g. $[3,6,7])$. The visible features of target lands are what are traditionally assessed, Daniel [8]. The expert/design approach assumes that scenic beauty can be objectively analyzed and translated into design formulas by trained experts (e.g. art, design, ecology, and resource management fields), Zube et al. [7]. Experts' judgments are assumed to be surrogates for public opinions [9]. For example, visual design features (e.g. form, line, vividness, and unity), derived from an art perspective, can be the descriptor variables /indicators of landscape quality $[9,10,11]$. The natural, unmodified ecosystems are strongly implicitly assumed to carry the highest value of landscape quality from an ecological perspective $[12,13]$. The public perception-based approach assumes that the high aesthetic values, reported by a combination of human observers' 
perceptions, interpretations, or feelings stimulated by landscapes or landscape properties, represent the high visual landscape quality, Daniel [8]. In addition, the direct participation of potential users, the public, is emphasized to incorporate the public's local knowledge, Kent and Elliot [14]. Between these two approaches, the expert/design approach is dominant in public land management practices, Daniel [8], including scenic highway programs (e.g. [15, 16]) and scenic byway programs (e.g. $[17,18])$. This dominance might result from certain aspects of its operation: (1) simple and explicit guidelines, (2) fewer reviewers and expenditures, and shorter timelines, compared with the publicperception assessment approach. However, Brown et al. [19] question the reliability of the experts' judgments to act as surrogates of the public's opinions. Thus, the qualification and reliability of individual expert judgments to represent the public's opinions should be examined.

\section{Systematic landscape evaluation framework in Taiwan}

In the context of limited available land for urban development and traffic demand in Taiwan, the goals of natural and cultural land conservation as well as tourism development are included in road development. Thus, the scenic road concept is used for implementing these goals. As Taiwan administration belongs to top-down governance, a systematic landscape evaluation framework can be an important link between nationwide planning and local detailed projects.

\subsection{Methodology}

The evaluation framework is primarily developed from an expert/design assessment approach, but includes the involvement of public officials to examine experts' evaluation. This evaluation framework employs a multi-stepped designation process, focusing on natural, cultural, and recreational service resources along with road safety considerations. Then, the statement of scenic beauty is formulated by descriptors regarding these foci.

\subsubsection{Delimitation of the evaluated scope of scenic road corridors}

Visual quality comprises both the nature of the landscape and the responses of viewers to the landscape, Chenoweth and Gobster [20]. In this study, the boundaries of scenic road corridors are defined by the visible range (viewshed) viewed by road users. Viewshed analysis by overlapping maps of topography, vegetation, and land use is used to determine the limits of the affected visual environments.

\subsubsection{Environmental inventory}

The environmental inventory contains information on: (1) natural resourcesland form, hydrology, land cover, and biota; (2) cultural resources-land use types, architectural structures/landscaping, historical sites/structures/artifacts, and indigenous districts/structures/artifacts; (3) visual resources-visual characters (created by the arrangement of the physical components of natural and cultural resources in the landscape), visual sequential experiences along roads; 
(4) recreational service resources - the number and the service level of recreational areas within a certain distance along road corridors; (5) road service level-traffic capacity and safety.

\subsubsection{Delimitation of landscape assessment units}

The preliminary work to delimit landscape assessment units involved overlapping the maps of land-use types, altitude, slope, and vegetative cover. This overlapping work can subdivide the defined scenic road corridors into a series of distinct visual landscape units. It also suggests potential viewpoints, which include either vantage points or places to detect fragile and/or significant landscapes to be impacted. Field surveys were taken to validate the assessment units and selected viewpoints.

\subsubsection{Selected evaluators}

The evaluators for the landscape assessment were selected from the professionals specialized in landscape architecture, architecture, ecology, recreation, and resource management fields. They are familiar with scenic road issues. These evaluators rated the relevant criteria and determined the relative weights of each criterion for the calculation of assessment values. Then, the experienced public officials from central and local road relevant agencies examined the experts' suggestions for bridging the gap between experts' preference and local knowledge.

\subsubsection{Evaluation criteria and numeric rating}

The designation criteria for scenic roads include (1) a landscape quality dimension, measured by visual landscape quality, visual sequential experiences, ecological significance, and cultural significance, and (2) a recreational value dimension, measured by the number and service level of neighboring recreational areas as well as the safety and service level of scenic road segments. The descriptions and numeric ratings for each criterion are shown in table 1 and table 2 .

Table 1: Numeric ratings and general description of landscape quality dimension.

\begin{tabular}{|l|l|c|l|l|}
\hline Criterion & Visual landscape quality \\
\hline Descriptor & Definition & Rating/General description \\
\hline Vividness & $\begin{array}{l}\text { The viewers memorability } \\
\text { is associated with visually } \\
\text { distinctive landscape } \\
\text { patterns which are }\end{array}$ & 9 & $\begin{array}{l}\text { An unique visual impression is received from the combination } \\
\text { of extremely vivid/unforgettable landscape elements/patterns. }\end{array}$ & $\begin{array}{l}\text { A rare visual impression is received from the combination } \\
\text { of primarily vivid landscape elements/patterns. }\end{array}$ \\
\cline { 2 - 5 } $\begin{array}{l}\text { composed by diverse and/or } \\
\text { contrast landscape elements } \\
\text { such as land form, }\end{array}$ & 5 & $\begin{array}{l}\text { A pleasure visual impression is received from the } \\
\text { combination of well vivid landscape elements/patterns. }\end{array}$ \\
\cline { 2 - 4 } $\begin{array}{l}\text { vegetative cover, water } \\
\text { body, and human structures. } \\
\text { This visual impression is } \\
\text { immediate and lasting. }\end{array}$ & 3 & $\begin{array}{l}\text { A common visual impression is received from the } \\
\text { combination of moderately vivid landscape elements/patterns. }\end{array}$ \\
\cline { 2 - 4 } & $\begin{array}{l}\text { No visual impression is generated from the combination of } \\
\text { nominally vivid landscape elements/patterns. }\end{array}$ \\
\hline
\end{tabular}


Table 1: Continued.

\begin{tabular}{|c|c|c|c|}
\hline Criterion & \multicolumn{3}{|l|}{ Visual landscape quality } \\
\hline Descriptor & Definition & \multicolumn{2}{|r|}{ Rating/General description } \\
\hline \multirow[t]{5}{*}{ Intactness } & \multirow{5}{*}{$\begin{array}{l}\text { It is defined as the } \\
\text { integrity of the visual } \\
\text { order in overall scene } \\
\text { content, composed of } \\
\text { natural and/or human built } \\
\text { environments for } \\
\text { examining the level of } \\
\text { visual disturbance from } \\
\text { the development. }\end{array}$} & 9 & $\begin{array}{l}\text { The overall scene content is extremely intact. No noticeable } \\
\text { or distracting disturbances exist on the visual environment. }\end{array}$ \\
\hline & & 7 & $\begin{array}{l}\text { The overall scene content is primarily intact. Little noticeable } \\
\text { or distracting disturbances exist on the visual environment. }\end{array}$ \\
\hline & & 5 & $\begin{array}{l}\text { The overall scene content is well intact. Some noticeable or } \\
\text { distracting disturbances exist on the visual environment. }\end{array}$ \\
\hline & & 3 & $\begin{array}{l}\text { The overall scene content is moderately intact. Noticeable or } \\
\text { distracting disturbances exist on the visual environment. }\end{array}$ \\
\hline & & 1 & $\begin{array}{l}\text { The overall scene content is nominally intact. Seriously noticeable } \\
\text { or distracting disturbances exist on the visual environment. }\end{array}$ \\
\hline \multirow[t]{5}{*}{ Harmony } & \multirow{5}{*}{$\begin{array}{l}\text { The viewers feel balance } \\
\text { and harmony from the } \\
\text { coexistence of different } \\
\text { landscape elements from a } \\
\text { landscape scene. }\end{array}$} & 9 & $\begin{array}{l}\text { The different landscape elements in a scene blend together } \\
\text { into an extremely high visual landscape totality to form a } \\
\text { cohesive and unique experience for viewers. }\end{array}$ \\
\hline & & 7 & $\begin{array}{l}\text { The different landscape elements in a scene blend together } \\
\text { into a primarily high visual landscape totality to form a } \\
\text { complementary and pleasing experience for viewers. }\end{array}$ \\
\hline & & 5 & $\begin{array}{l}\text { The different landscape elements in a scene blend together } \\
\text { into a highly visual landscape totality to form a great } \\
\text { experience for viewers. }\end{array}$ \\
\hline & & 3 & $\begin{array}{l}\text { The different landscape elements in a scene blend together } \\
\text { into a moderately visual landscape totality to form a common } \\
\text { experience for viewers. }\end{array}$ \\
\hline & & 1 & $\begin{array}{l}\text { The different landscape elements in a scene blend together } \\
\text { into a nominally visual landscape totality to form a unpleasing } \\
\text { experience for viewers. }\end{array}$ \\
\hline Criterion & \multicolumn{3}{|c|}{ Visual sequential experiences } \\
\hline \multirow{5}{*}{$\begin{array}{l}\text { Sequent } \\
\text { unity }\end{array}$} & \multirow{5}{*}{$\begin{array}{l}\text { The viewers feel balance } \\
\text { and harmony from the } \\
\text { transference of different } \\
\text { landscape scenes, } \\
\text { represented by landscape } \\
\text { compositions and their } \\
\text { formed spatial structures, } \\
\text { along driving. }\end{array}$} & 9 & $\begin{array}{l}\text { The sequential landscape scenes reveal an extremely } \\
\text { appropriate balance/harmony for viewers. }\end{array}$ \\
\hline & & 7 & $\begin{array}{l}\text { The sequential landscape scenes reveal a highly appropriate } \\
\text { balance/harmony for viewers. }\end{array}$ \\
\hline & & 5 & $\begin{array}{l}\text { The sequential landscape scenes reveal a well appropriate } \\
\text { balance/harmony for viewers. }\end{array}$ \\
\hline & & 3 & $\begin{array}{l}\text { The sequential landscape scenes reveal a moderately } \\
\text { appropriate balance/harmony for viewers. }\end{array}$ \\
\hline & & 1 & $\begin{array}{l}\text { The sequential landscape scenes reveal an inappropriate } \\
\text { balance/harmony for viewers. }\end{array}$ \\
\hline \multirow{5}{*}{$\begin{array}{l}\text { Sequent } \\
\text { variety }\end{array}$} & \multirow{5}{*}{$\begin{array}{l}\text { A diverse or mixed visual } \\
\text { experiences of viewers, } \\
\text { received from the } \\
\text { transference of sequential } \\
\text { landscape scenes. Scenic } \\
\text { variety can be associated } \\
\text { with the diversity of colors, } \\
\text { textures, shapes, masses, } \\
\text { forms, and shapes, formed } \\
\text { by the composition and } \\
\text { structures of sequential } \\
\text { landscape scenes. }\end{array}$} & 9 & $\begin{array}{l}\text { The sequential landscape scenes reveal an extremely high } \\
\text { level of sequent variety for viewers. }\end{array}$ \\
\hline & & 7 & $\begin{array}{l}\text { The sequential landscape scenes reveal a high level of sequent } \\
\text { variety for viewers. }\end{array}$ \\
\hline & & 5 & $\begin{array}{l}\text { The sequential landscape scenes reveal a moderate level of } \\
\text { sequent variety for viewers. }\end{array}$ \\
\hline & & 3 & $\begin{array}{l}\text { The sequential landscape scenes reveal an low level of } \\
\text { sequent variety for viewers. }\end{array}$ \\
\hline & & 1 & $\begin{array}{l}\text { The sequential landscape scenes reveal an extremely low level } \\
\text { of sequent variety for viewers. }\end{array}$ \\
\hline Criterion & \multicolumn{3}{|c|}{ Ecological and cultural significance } \\
\hline Descriptor & Definition & & ing/General description \\
\hline \multirow[t]{5}{*}{ Uniqueness } & \multirow{5}{*}{$\begin{array}{l}\text { The relative scarcity or } \\
\text { abundance of a certain } \\
\text { type of ecological/cultural } \\
\text { resources along road } \\
\text { corridors }\end{array}$} & 9 & Nothing elsewhere can compare with it/them. \\
\hline & & 7 & The type of resources is rare but not unique within the country. \\
\hline & & 5 & The status of uniqueness is regional level. \\
\hline & & 3 & The status of uniqueness is local level. \\
\hline & & 1 & The type of resource is common cross the country. \\
\hline \multirow{5}{*}{$\begin{array}{l}\text { Represent- } \\
\text { ative }\end{array}$} & \multirow{5}{*}{$\begin{array}{l}\text { A certain type of } \\
\text { ecological/cultural } \\
\text { resources can represent the } \\
\text { characteristics of the } \\
\text { places which could be } \\
\text { nationwide, regional, or } \\
\text { local level, to generate the } \\
\text { sense of place. }\end{array}$} & 9 & The type of resources can represent a nationwide image. \\
\hline & & 7 & $\begin{array}{l}\text { The type of resources can strongly represent a regional/local } \\
\text { image. }\end{array}$ \\
\hline & & 5 & The type of resources can represent a regional/local image. \\
\hline & & 3 & $\begin{array}{l}\text { The type of resources can partially represent a regional/local } \\
\text { image. }\end{array}$ \\
\hline & & 1 & $\begin{array}{l}\text { The type of resources can nominally represent a regional/local } \\
\text { image. }\end{array}$ \\
\hline
\end{tabular}


Table 2: Numeric ratings and general description of recreational value dimension.

\begin{tabular}{|c|c|c|}
\hline \multicolumn{3}{|c|}{ Recreational service quality } \\
\hline Descriptor & \multicolumn{2}{|c|}{ Rating/General description } \\
\hline \multirow{5}{*}{$\begin{array}{l}\text { The number of } \\
\text { neighbouring park } \\
\text { and recreational areas }\end{array}$} & 9 & The road corridor connects more than 5 parks/recreational areas. \\
\hline & 7 & The road corridor connects $2 \sim 5$ park /recreational areas. \\
\hline & 5 & Each end of the road corridor connects 1 park/ recreational area. \\
\hline & 3 & The road corridor connects only one park/recreational area. \\
\hline & 1 & The road corridor connects no park/recreational area. \\
\hline \multirow{5}{*}{$\begin{array}{l}\text { The level of } \\
\text { recreational quality } \\
\text { of neighbouring park } \\
\text { and recreational areas } \\
\text { along road corridors }\end{array}$} & 9 & $\begin{array}{l}\text { More than } 3 \text { of the legitimately public/private park/recreational areas connected } \\
\text { by the road corridor are rated as the excellent or great level. }\end{array}$ \\
\hline & 7 & $\begin{array}{l}3 \text { of the legitimately public/private park/recreational areas connected by the road } \\
\text { corridor are rated as the excellent or great level. }\end{array}$ \\
\hline & 5 & $\begin{array}{l}2 \text { of the legitimately public/private park/recreational areas connected by the road } \\
\text { corridor are rated as the excellent or great level. }\end{array}$ \\
\hline & 3 & $\begin{array}{l}1 \text { of the legitimately public/private park/recreational areas connected by the road } \\
\text { corridor is rated as the excellent or great level. }\end{array}$ \\
\hline & 1 & $\begin{array}{l}\text { None of the legitimately public/private park/recreational areas connected by the } \\
\text { road corridor are rated as the excellent or great level. }\end{array}$ \\
\hline \multirow{5}{*}{$\begin{array}{l}\text { The service status of } \\
\text { related landscape } \\
\text { facilities to scenic } \\
\text { road sightseeing } \\
\text { along road corridors }\end{array}$} & 9 & $\begin{array}{l}\text { Along road corridors overlooking decks are located at the vantage viewpoints } \\
\text { with beautiful scenery, and rest areas are provided in the available areas. Also, } \\
\text { the booklets and interpretation signs about scenic landscapes are well provided. }\end{array}$ \\
\hline & 7 & $\begin{array}{l}\text { Along road corridors overlooking decks are located at the vantage viewpoints } \\
\text { with beautiful scenery and the booklets and interpretation signs about scenic } \\
\text { landscapes are well facilitated. }\end{array}$ \\
\hline & 5 & $\begin{array}{l}\text { Along road corridors rest areas are provided in the available areas. The } \\
\text { interpretation systems about significant scenic landscapes are provided. }\end{array}$ \\
\hline & 3 & $\begin{array}{l}\text { Along road corridors turnout lanes are provided in the available areas. The } \\
\text { interpretation systems about significant scenic landscapes are briefly facilitated. }\end{array}$ \\
\hline & 1 & $\begin{array}{l}\text { Along road corridors none of the overlooking places, rest areas, and } \\
\text { interpretation systems are provided. }\end{array}$ \\
\hline Criterion & \multicolumn{2}{|c|}{ Road service quality } \\
\hline \multirow{5}{*}{$\begin{array}{l}\text { The level of road } \\
\text { quality in terms of } \\
\text { traffic capacity }\end{array}$} & 9 & Grade A quality on holidays \\
\hline & 7 & Grade B quality on holidays \\
\hline & 5 & Grade C quality on holidays \\
\hline & 3 & Grade D quality on holidays \\
\hline & 1 & Grade E or lower quality on holidays \\
\hline \multirow[t]{5}{*}{$\begin{array}{l}\text { The level of road } \\
\text { safety }\end{array}$} & 9 & $\begin{array}{l}\text { The whole section of the road segment meets the legitimate engineering } \\
\text { standards of road safety. No risks of landslides occur along road corridors. }\end{array}$ \\
\hline & 7 & $\begin{array}{l}\text { The whole section of the road segment meets the legitimate engineering standards } \\
\text { of road safety. The risk of landslides only occurs at few spots along road corridors. }\end{array}$ \\
\hline & 5 & $\begin{array}{l}\text { Only few sections of the road segment do not meet the legitimate engineering } \\
\text { standards of road safety. No risks of landslides occur along road corridors. }\end{array}$ \\
\hline & 3 & $\begin{array}{l}\text { A few sections of road segments do not meet the legitimate engineering standards of } \\
\text { road safety. No risks of landslides occur along road corridors. }\end{array}$ \\
\hline & 1 & $\begin{array}{l}\text { A few sections of road segments do not meet the legitimate engineering standards of } \\
\text { road safety. The risk of landslides occurs at a few spots along road corridors. }\end{array}$ \\
\hline
\end{tabular}

\subsubsection{Calculation of scenic road assessment values}

In the landscape quality dimension, the relative weight is the same for each of the nine descriptors reflecting its relative importance. In the visual landscape quality criterion, three descriptors are evaluated by the delimitated landscape assessment units. The relative weight of each landscape assessment unit is determined by its relative length to the whole road segment length. The formula for the calculation of landscape quality values is shown below: 
Landscape quality value (LQA)/each scenic road segment with " $n$ " assessment units=

$\left\{\sum_{1}^{n}[(\right.$ vividness+intactness+harmony) of each assessment unit/3 $] *$ its length weight coefficient $(\%)]\}+[$ (sequent unity + sequent variety $) / 2]+$ $[($ ecological uniqueness + ecological representative + cultural uniqueness + cultural representative)/4]

The rank of landscape quality value: $L Q A \leq 4$, Low; $4<L Q A \leq 7$, medium;

$$
L Q A>7 \text {, high }
$$

In the recreational value dimension, the relative weight is the same for each of the five descriptors, again reflecting relative importance. The formula for the calculation of recreational quality value is shown as below.

Recreational quality value (RQA) /each scenic road segment= [(the sum of the values of five descriptors value) $/ 5$ ]

The rank of service quality value: $R Q A \leq 4$, Low; $4<R Q A \leq 7$, medium; $R Q A>7$, high

For calculating the values for scenic road assessment, the relative weights for landscape quality value (LQA) and recreational quality value (RQA) are two to one because landscape quality is the primary factor to qualify a scenic road. Selected experts suggest that three levels of scenic road quality should be applied. Nevertheless, the selected public officials, considering the limited lands and budget for conservation in Taiwan, indicate that two levels (qualified, not qualified) of scenic road value should be applied. Then, the qualified scenic roads can receive more official resources to preserve their visual character. The formula for the calculation of scenic road values follows:

Scenic road assessment value $(\mathrm{SRV})=\left(\mathrm{LQA}^{*} 2+\mathrm{RQA} * 1\right) / 3$

The rank of scenic road value:

$$
\begin{array}{ll}
S R V \leq 5 & \text { ordinary road; } \\
S R V>5 & \text { national level scenic road }
\end{array}
$$

\subsection{Results}

The result of computing the scenic assessment values for 78 existing scenic road segments suggests that only 22 scenic road segments are rated as national level scenic road as seen in fig. 2 . The rest of the existing scenic road segments are considered as ordinary roads. However, conclusions from a conference that involved relevant public officials from nationwide road planning, construction, and management agencies suggests that the rank of scenic value should be adjusted to contain three levels ( $\mathrm{SRV}<4,4 \leqq \mathrm{SRV} \leqq 5, \mathrm{SRV}>5$ ), and include the medium level as potential scenic roads. The reasons for this adjustment include: (1) reducing the landscape quality gap between a national level scenic road and an ordinary road where they link together, (2) strengthening the links between the national level scenic roads and the official regional travelling package system for encouraging tourism and local community development, (3) providing 
flexibility for the adjustment of operation or management to respond to the public's opinions. After this adjustment, 8 roads with scenic road potential have been designated, and two road segments have been newly designated among these 8 road segments.

\section{Conclusion}

A systematic evaluation framework for scenic roads not only suggests a holistic and systematic scenic road system, but also provides a communication platform for experts, public officials, and local communities. The implementation of this framework can address the traditional problems for implementing scenic roads in Taiwan originated primarily from a lack of consensus for operating and managing scenic roads among relevant agencies. It can also address the issue that the landowners and developers within the range of scenic corridors rarely notice or are concerned that their new developments can impact irrecoverable scenic landscape quality. In addition, referring to this evaluation system, the authorities that are in charge of scenic roads can develop relevant management activities, and negotiate or defend visual quality objectives in multiple-resource decision contexts. By participating in or noticing the processes of operating the evaluation framework, public officials and the public can raise their knowledge/concerns about scenic roads and environmental conservation. Due to using an expert/design assessment approach, the evaluation framework should maintain a flexibility to finalize the suggested scenic road system for responding to the public's opinions. In addition, this system also requires a periodical examination for adapting to contemporary circumstances.

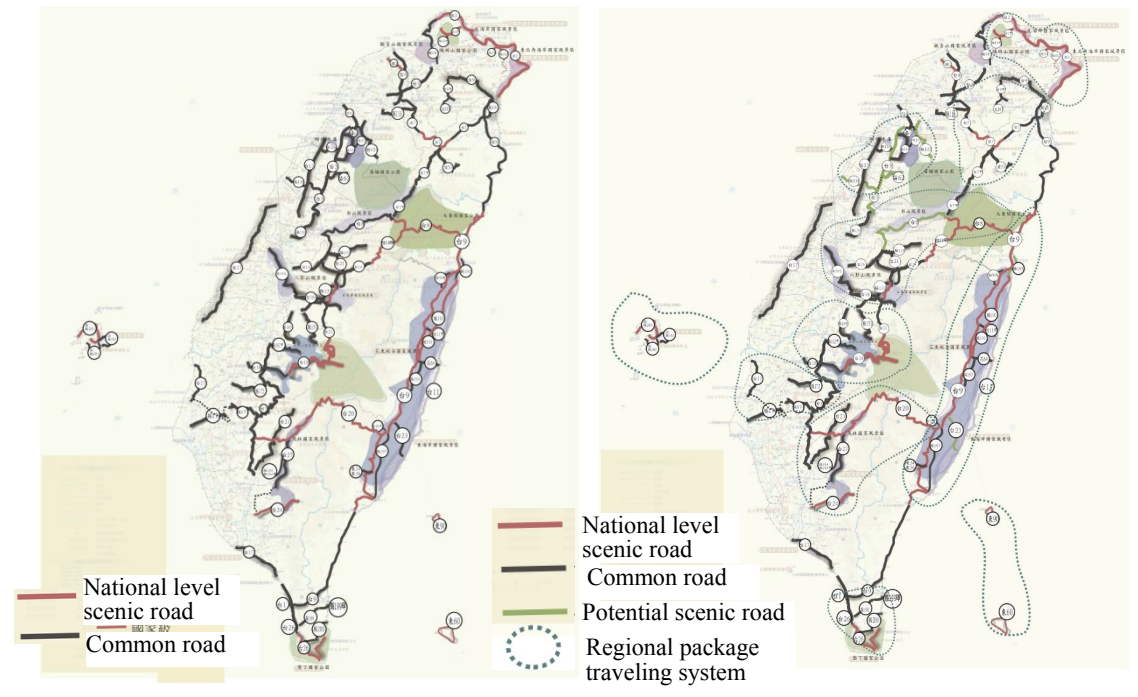

Figure 2: Established scenic road Figure 3: Established scenic road system (draft). system (final). 


\section{Reference}

[1] Taiwan Government Information Office, http://www.gio.gov.tw/taiwanwebsite/5-gp/brief/

[2] Parsons, R. \& Daniel, T. C., Good looking: In defense of scenic landscape aesthetics. Landscape and Urban Planning, 60(1), pp. 43-56, 2002.

[3] Daniel, T.C. \& Vining, J., Methodological issues in the assessment of landscape quality. Behavior and the Natural Landscape, eds. I. Altman \& J. Wohlwill, Plenum Press: New York, 1983.

[4] Zube, E.H., Scenery as a natural resource: implications of public policy and problems of definition, description, and evaluation. Landscape Architecture, January, pp. 126-132, 1973

[5] Zube, E.H., Environmental evaluation: Perception and public policy, Brooks/Cole Publishing Company: Monterey, CA, 1980.

[6] Arthur, L.M., Daniel, T.C. \& Boster, R.S., Landscape assessment: A critical review of research and methods. Landscape Management, 4, pp. 109-129, 1977.

[7] Zube, E.H., Sell, J.L. \& Taylor, J.G., Landscape perception: research application and theory. Landscape Planning, 9, pp. 1-33, 1982.

[8] Daniel, T. C., Whither scenic beauty? Visual landscape quality assessment in the 21st century. Landscape and Urban Planning, 54(1-4), pp. 267-281, 2001.

[9] Clay, G. R. \& Smidt, R. K, Assessing the validity and reliability of descriptor variables used in scenic highway analysis. Landscape and Urban Planning, 66(4), pp. 239-255, 2004.

[10] Bureau of Land Management (BLM), Visual Resource Inventory; BLM Manual Handbook 8410-1. US Department of the Interior, Office of Public Affairs, Washington, DC, 1986

[11] Colorado Scenic and Historic Byways Commission, Design Guidelines for Visual Resources Along Scenic and Historic Byways, Colorado Department of Transportation, 2002.

[12] Smardon, R.C., Assessing visual - cultural values of inland wetlands in Massachusetts. Landscape Assessment: Values, Perceptions and Resources, eds. E.H. Zube, R.O. Brush \& J.G. Fabos, Dowden, Hutchinson and Ross: Stroudsburg, PA, pp. 289-318, 1975.

[13] Guidelines for Official Designations of Scenic Highways (1996); California Department of Transportation (Caltrans), online. www.dot.ca.gov/hq/LandArch/scenic/shpg1.htm.

[14] Kent, R. L. \& Elliott, C. L, Scenic routes linking and protecting natural and cultural landscape features: A greenway skeleton. Landscape and Urban Planning, 33(1-3), pp. 341-355, 1995.

[15] Arizona Department of Transportation (Arizona DOT), Application Procedures for Designation of Parkways, Historic and Scenic Roads in Arizona. Parkways; Historic and Scenic Roads Advisory Committee Publication, Phoenix, Arizona, 1993. 
[16] Colorado Department of Transportation (Colorado DOT), Frisco to Breckenridge: State Highway 9 Draft Environmental Impact Statement; Colorado Department of Transportation, 2002.

[17] Federal Highway Administration (FHA), Byways Beginnings: Understanding, Inventorying, and Evaluating a Byway's Intrinsic Qualities; National Scenic Byways Program Publication, Washington, DC, 1999.

[18] Washington State Department of Transportation (Wash DOT), State Route 97-Pateros to the Canadian Border: Scenic Byway Application Visual Analysis Discipline Report; Washington State Department of Transportation, Olympia, WA, 2002.

[19] Brown, T., Keane, T. \& S. Kaplan, Aesthetics and management: bridging the gap. Landscape Urban Planning, 13, pp. 1-10, 1986.

[20] Chenoweth, R.E. \& Gobster, P.H., The nature and ecology of aesthetic experiences in the landscape. Landscape Journal, 9, pp. 1-8, 1990. 